\title{
Acute Orbital Cellulitis: A Case Series
}

\author{
*I D Singh ${ }^{1}$, Lt Col V Gupta ${ }^{2}$, S Gupta ${ }^{3}$ and Anubhav ${ }^{4}$ \\ ${ }^{1}$ Assistant Professor, Department of Otolaryngology, Command Hospital, India \\ ${ }^{2}$ Assistant Professor, Department of Otolaryngology, Command Hospital, India \\ ${ }^{3}$ Resident, Department of Otolaryngology, Command Hospital, India \\ ${ }^{4}$ Resident, Department of Otolaryngology, Command Hospital, India
}

Submission: January 17, 2017; Published: January 24, 2017

*Corresponding author: I D Singh, Asst Prof, Department of Otolaryngology Head \& Neck surgery, Command Hospital (Southern Command), Pune, India 411040, Tel: +91-7767834137; Email: dridsingh@hotmail.com

\section{Abstract}

Orbital cellulitis is an important and frequent complication of rhinosinusitis. If not treated adequately and timely, it can lead to loss of vision and life threatening complications. We describe three peculiar cases of orbital cellulitis with favorable outcome. An endoscopic approach is favored if orbital cellulitis is arising as a complication of rhinosinusitis. The nasal endoscopic approach is safe and quick way of addressing severe sub-periosteal abscess as well as sinus infections especially in the immunocompromised patients with poor general health conditions. Medial orbital decompression is achieved by removal of lamina papyracea, part of superolateral wall of sphenoid sinus wall and inferiomedial wall of the orbit so that orbital contents can be decompressed.

Keywords: Bacterial Orbital Cellulitis, Endoscopic orbital decompression, CSF repair, HIV; Diabetes

\section{Introduction}

The pre and post septal cellulitis, subperiosteal and orbital abscess are important and serious complications of rhinosinusitis. If not treated adequately and timely, they can lead to loss of vision and life threatening complications. We describe four cases of acute orbital cellulitis who all presented with short duration of proptosis and vision loss. The early intervention in the form of endoscopic sinus clearance and medial orbital decompression along with targeted antibiotics can bring the favorable outcomes in such patients.

\section{Case 1}

A 45 years old female, known case of HIV, not on antiretroviral therapy, presented with complaints of painful swelling left eye and rapidly progressive loss of vision for past 07 days.

Examination: Left eye: Proptosis, restricted ocular movements and decreased vision (perception of light) was noted on examination. The pupillary reflex was sluggish. Necrotizing fasciitis of lower eyelid was also present. Right eye was essentially normal. Nasal endoscopy revealed frank purulent discharge was seen originating from the spheno-ethmoid recess.

Imaging: Contrast Enhanced Computed Tomography (CECT) scan was suggestive of left maxillary sinusitis with evidence of subperiosteal collection in the orbit. Magnetic resonance imaging (MRI) orbit, brain and paranasal sinuses revealed proptosis of left eye with peri-orbital soft tissue swelling associated with inflammatory mucosal thickening in the left side paranasal sinuses.

Bacteriology (Nasal Swab): Swab of the discharge was taken. Culture and sensitivity showed Pseudomonas aeruginosa which was resistant to Amoxicillin-Clavulanic acid, PiperacillinTazobactam, Ticaracillin-Sulbactum, First and second generation Cephalosporins, Carbapenems, Aminoglycosides, Fluoroquinolones, Colistin, Trimethoprim- Sulfamethoxazole.

Viral markers: The serology was positive for HIV- 1.

Medical management: Parenteral antibiotic cover was given with Ceftazidime, Imipenem, Clindamycin and Metronidazole.

Surgical management: Urgent endonasal endoscopic sinus surgery was done with clearance of maxillary, ethmoidal, frontal and sphenoidal sinuses and involving removal of medial orbital wall. The orbit was opened and decompressed removing the orbital fat till medial rectus muscle. The entire lamina papyracea and medial part of roof of maxillary sinus was removed. Sphenoid sinus was opened widely upto the orbital apex and optic nerve 
was decompressed by opening its sheath. Also, lower eyelid wound debridement along with lateral cantholysis was done. The patient's vision improved postoperatively to $6 / 24$ and she underwent staged tarsorrhaphy later.

\section{Case 2}

A 73 years old male, known case of uncontrolled diabetes mellitus presented with complaints of painful swelling around right eye and complete loss of vision of 20 days duration.

Examination: Proptosis, complete ophthalmoplegia and no perception of light in right eye. Nasal endoscopy showed mucopus in right middle meatus and in spheno-ethmoidal recess.

Imaging: Contrast enhanced CT scan of orbit and paranasal sinuses showed extensive mucosal involvement of sphenoid, maxillary and ethmoidal sinuses bilaterally with intra-orbital extension of infection in right orbit with thickening of right optic nerve.

Bacteriology (Nasal Swab): Staphylococcus aureus

Medical management: Antibiotic cover with Linezolid, Clindamycin, Cefoperazone and Metronidazole was given.

Surgical management: Urgent endonasal endoscopic sinus surgery and clearance of all paranasal sinuses and decompression of the right orbit into nasal cavity was done. The optic nerve was decompressed by opening its sheath along the length near the orbital apex. Intraoperatively, anterior cranial base dura was detected to be unhealthy with granulations.

The unhealthy dura with granulation tissue was excised which resulted in an iatrogenic cerebrospinal fluid (CSF) leak.
The CSF leak was repaired by 'sandwich technique' using two layers of nasal septal bone and one layer of septal cartilage. These layers were reinforced with fibrin tissue sealant. The defect was covered with pedicled middle turbinate mucosal flap. Postoperatively, the patient had partial return of upper eyelid movements and perception of light in his operated eye. He had no signs of any CSF leak and serial nasal endoscopy showed good healing and mucosalization of nasal cavity.

\section{Case 3}

A 6 years old girl with no known co-morbidities presented with painful swelling around left eye and diminution of vision (left eye) and left frontal sinus tenderness with erythema of skin over left frontal region of 10 days' duration.

Examination: Revealed proptosis left eye. Vision was reduced to $6 / 60$. There was no restriction of eye movements. Nasal endoscopy showed frankpus in middle meatus.

Imaging: Contrast enhanced CT scan showed extensive mucosal involvement of maxillary and ethmoidal sinuses on left with intra-orbital extension of infection displacing the eyeball.

Bacteriology: Staphylococcus aureus.

Medical management: Antibiotic cover with Linezolid, Clindamycin and Metronidazole was given.

Surgical management- Urgent endonasal endoscopic sinus surgery and clearance of all sinuses and Draf2 procedure for frontal sinus on left side was done. The orbital decompression was done by removing the infero-medial part of floor of the orbit as well as the medial wall upto the medial rectus muscle. Post-operative, the patient's vision improved to $6 / 6$ and she made an uneventful recovery.

Table 1: Comparison of the cases of acute rhinosinusitis with orbital complications.

\begin{tabular}{|c|c|c|c|c|}
\hline & Case 1 & Case 2 & Case 3 & Case 4 \\
\hline Age \& Sex & $45 / \mathrm{F}$ & $73 / \mathrm{M}$ & $06 / F$ & $51 / \mathrm{F}$ \\
\hline Comorbidities & $\mathrm{HIV}+$ & Type II Diabetes Mellitus & Nil & Type II Diabetes Mellitus \\
\hline Bacteriology & $\begin{array}{c}\text { Pseudomonas } \\
\text { aeruginosa }\end{array}$ & Staph aureus & Staph aureus & Serratio Marcescens, E coli \\
\hline Imaging & CECT \& MRI & CECT & CECT & NCCT \& MRI \\
\hline Antibiotics & $\begin{array}{l}\text { Ceftazidime } \\
\text { Imipenem } \\
\text { Metronidazole } \\
\text { Clindamycin } \\
\end{array}$ & $\begin{array}{c}\text { Linezolid } \\
\text { Clindamycin } \\
\text { Cefoperazone } \\
\text { Metronidazole }\end{array}$ & $\begin{array}{c}\text { Linezolid } \\
\text { Clindamycin } \\
\text { Metronidazole }\end{array}$ & $\begin{array}{l}\text { Piperacillin- } \\
\text { tazobactam } \\
\text { Imipenem }\end{array}$ \\
\hline Vision (Pre-op) & PL+ & PL- & $6 / 60$ & PL+ \\
\hline Vision (Post-op) & $6 / 24$ & PL+ & $6 / 6$ & $\mathrm{PL}+, \mathrm{PR}$ inaccurate \\
\hline Surgery & $\begin{array}{l}\text { Endoscopic sinus surgery + } \\
\text { Orbital decompression }\end{array}$ & $\begin{array}{l}\text { Endoscopic sinus surgery + } \\
\text { Orbital decompression }\end{array}$ & $\begin{array}{l}\text { Endoscopic sinus surgery + } \\
\text { Orbital decompression }\end{array}$ & $\begin{array}{c}\text { Endoscopic sinus } \\
\text { surgery + Medial Orbital } \\
\text { decompression }\end{array}$ \\
\hline
\end{tabular}




\section{Global Journal of Otolaryngology}

\section{Case 4}

A 51 years old lady, old case of Type II Diabetes Mellitus, presented with complaints of diminution of vision, swelling and proptosis of Left eye of 10 days duration.

Examination: Left eye: Vision was reduced (Perception of light present) and proptosis present. Pupils were fixed and dilated and eye movements were restricted. Nasal endoscopy revealed purulent discharge from middle meatus and frontal sinus ostia.

Imaging: NCCT PNS showed the presence of soft tissue density contents in Left frontal, maxillary, sphenoidal, anterior and posterior ethmoidal air cells and erosion of lamina papyracea on left side.

\section{Bacteriology: Serratia marcescens, E coli}

Management: The patient was started on Injectable Insulin and taken for Endoscopic Sinus Surgery and medial orbital decompression. Purulent discharge was found in Left frontal, maxillary, anterior ethmoidal, sphenoidal sinuses and Right posterior ethmoidal sinus. Lamina papyracea was found partially necrosed and its remnant was removed. Postoperative antibiotic cover was given with Inj Piperacillintazobactam and Inj Imipenem. Post-operative, the patient continued to have diminished vision (Perception of light present, inaccurate projection of rays). Ophthalmological consultation revealed Central Retinal Artery Occlusion (Lt) and Palsy of 6th cranial nerve (Table 1).

\section{Discussion}

Post septal orbital cellulitis is an acute inflammatory process with infection of orbital contents posterior to orbital septum. This is differentiated from pre septal cellulitis which involves infection of the eyelids and peri-orbital soft tissue anterior to the orbital septum. The orbital cellulitis may occur in following possible situations [1]:

a) Extension of the infection from peri-orbital structures (Paranasal sinuses, lacrimal sac).

b) Direct inoculation due to surgery or trauma.

c) Haematogenous spread from bacteremia. Orbital cellulitis is the most common and frequent complication of ethmoid rhinosinusitis in all age groups.

The predisposing factor in development of orbital cellulitis is sinus infection followed by trauma, orbital surgery/ implant, dacrocystitis, retained foreign body and dentalinfections [2]. Immunocompromised individuals generally have higher rates of complications and an overall poor outcome [3,4]. An increased incidence of orbital cellulitis is seen in winters because of increased incidence of rhinosinusitis. An increase has been noted in the frequency of orbital cellulitis caused by community acquired methicillin resistant Staphylococcus aureus infections $[5,6]$. Orbital cellulitis is seen more commonly in children than adults [7].
The most common underlying factor for its development is preceding rhinosinusitis, commonly involving ethmoid sinuses, with microbiology reflecting the association [8]. As the medial wall oforbit is very thin and porous, owing to the neurovascular channels, infections can easily extend to the neighbouring structures [9]. The pathogens commonly associated with orbital cellulitis are aerobic, non-spore forming bacteria like Streptococcus pneumoniae, Staphylococcus aureus, Streptococcus pyogenes and Haemophilus influenzae (mainly found in children). Pseudomonas, Klebsiella and enterococcus are less common etiological agents. Fungal infections are often seen in immune-compromised patients (Figures $1 \& 2$ ).
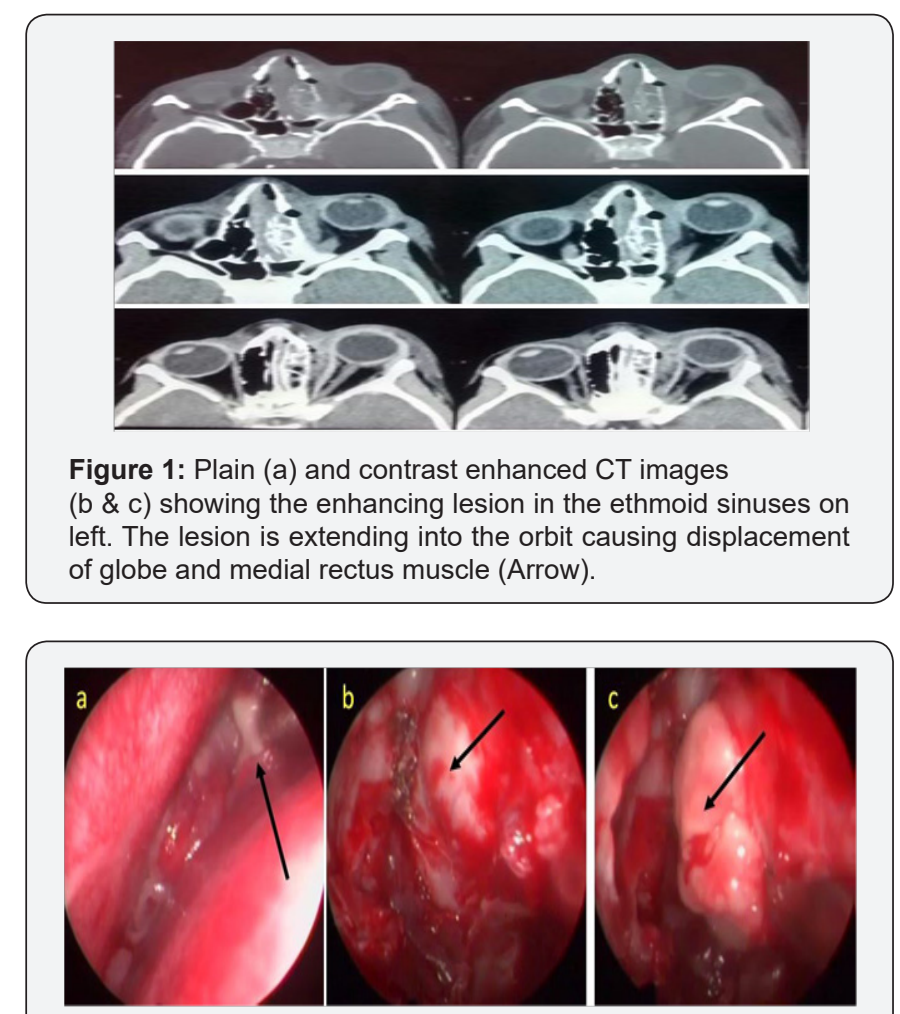

Figure 2: Intra-op images.

(a) Nasal endoscopy showing frank pun in left nasal cavity.

(b) Bulging orbital contents after removal of lamina papyracea.

(c) Orbital fat protruding into nasal cavity.

Differentiation between preseptal and postseptal cellulitis is often difficult at the initial presentation [10]. Orbital cellulitis may present as unilateral swelling of lids and conjunctiva, proptosis, painful ocular movements, diminution of vision, diplopia, sluggish pupillary reflexes, associated with fever and other toxemic features. Loss of vision in chronic rhinosinusitis can occur as a result of orbital complications such as central retinal artery occlusion, optic neuritis, corneal ulceration and pan-ophthalmitis [11]. Various imaging modality including ultrasonography and CT scan can be used for diagnosis. Although USG is quick and non-invasive but CT scan may be required to assess the evidence of rhinosinusinusitis and orbital involvement and remains investigation of choice. MRI is of limited value as it does not show the bony landmarks required for surgery $[12,13]$. 


\section{Global Journal of Otolaryngology}

Medical management includes parenteral antibiotic therapy. Bacteriological culture from conjunctiva and preseptal tissue might not be representative. In majority of cases surgical intervention is required. Surgery is indicated where there is evidence of orbital collection, in cases refractory to medical therapy, cases with compromised vision, where there is an atypical picture which warrants a diagnostic biopsy and in cases with complications (Table 2). Surgery often warrants a concurrent drainage of the infected sinuses [14]. Urgent endonasal endoscopic drainage with wide decompression of medial wall of orbit is indicated in patients who present with signs and symptoms of vision loss [15].

Table 2: Indications for surgery in orbital complication of orbital cellulitis.

\begin{tabular}{|c|c|}
\hline 1. & $\begin{array}{c}\text { Evidence of sub periosteal or intraorbital abscess in CT or } \\
\text { MRI. }\end{array}$ \\
\hline 2. & $\begin{array}{c}\text { Reduced visual acuity/reduced colour vision/affected } \\
\text { afferent pupillary reflex or inability to assess vision. }\end{array}$ \\
\hline 3. & $\begin{array}{c}\text { Progressive or worsening orbital signs (diplopia, } \\
\text { ophthalmoplegia, proptosis, swelling, and chemosis) after } \\
48 \text { hours of intravenous antibiotics. }\end{array}$ \\
\hline 4. & $\begin{array}{c}\text { Progressive or worsening of general condition (fever, } \\
\text { infection parameters) after } 48 \text { hours of intravenous } \\
\text { antibiotics. }\end{array}$ \\
\hline
\end{tabular}

Any child with proptosis, reduced or painful eye movement (ophthalmoplegia), or decreased visual acuity (initially manifesting itself with reduced green/red colour discrimination) should be evaluated with a CECT scan of the sinuses with orbital detail to distinguish between orbital cellulitis and intraorbital or subperiosteal abscess. In cases where an associated intracranial complication is suspected or in case of uncertainty, MRI can provide valuable additional information. All three conditions (orbital cellulitis, subperiosteal and intraorbital abscess) cause proptosis and limited ocular movement. Evidence of an abscess on the CT scan, worsening of orbital findings and impairment of vision (especially colour vision) after initial intravenous antibiotic therapy are indications for orbital exploration and drainage. Repeated ophthalmologic examinations of visual acuity should be done. Intravenous antibiotic therapy may be converted into oral when the patient has been a febrile for 48 hours and the ophthalmologic symptoms and signs are resolving (Figures 3 \& 4).

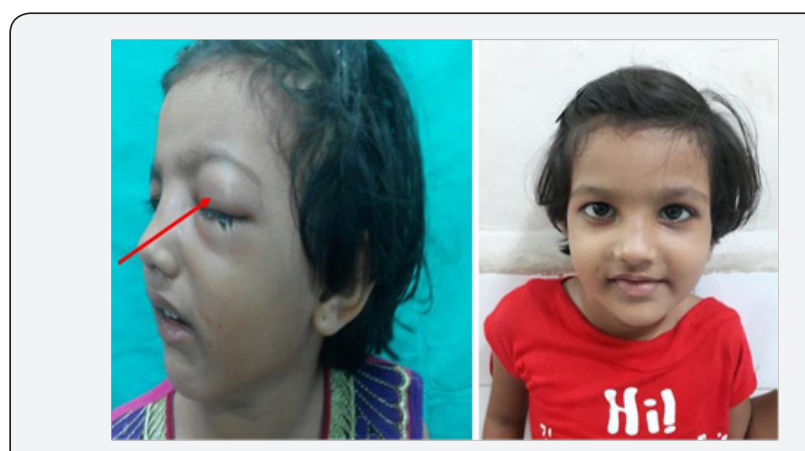

Figure 3: Perioperative and post op day 7 photos of the patient. The peri-orbital edema (shown by arrow) subsided completely after the surgery.

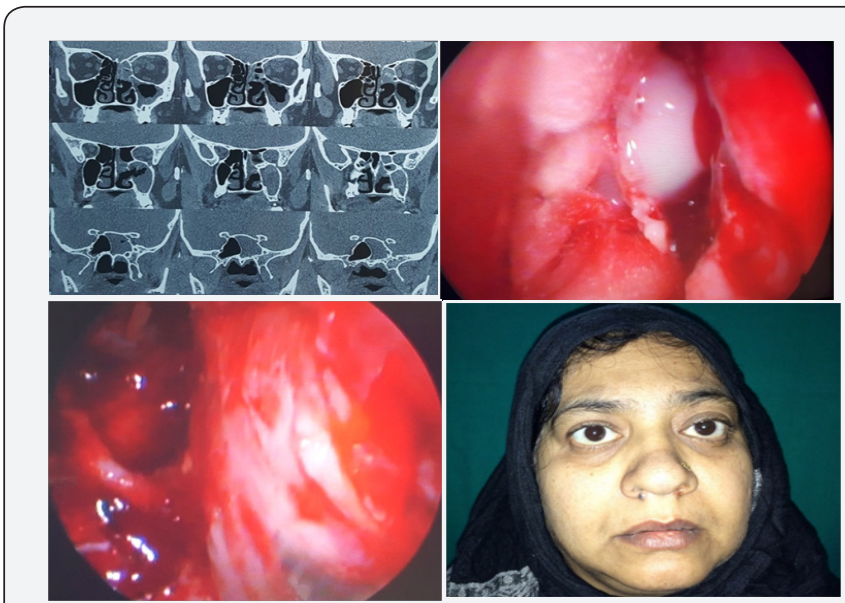

Figure 4: (a) Nasal endoscopy showing mucopus in nasal cavity. (b) pre-op NCCT PNS showing involvement of left side paranasal sinuses.

(c) Intra-op endoscopic sinus surgery and orbital decompression. (d) Post-op photo of the patient.

An endoscopic approach is favored if orbital cellulitis is arising as a complication of sinus disease. The nasal endoscopic approach is safe and quick way of addressing the severe subperiosteal abscess as well as sinus infections especially in the immunocompromised patients with poor general health conditions. The medial decompression is achieved by removal of lamina papyracea; part of superolateral part of sphenoid sinus wall and inferomedial wall of the orbit so that orbital contents can be decompressed into nasal cavity. The other advantages of endonasal endoscopic approach are that optic nerve decompression and repair of skull base or CSF leaks can be done simultaneously. However, in presence of intracranial complications, a combined approach is recommended. There have been a number of recent studies showing good outcomes with intravenous antibiotics in small children with subperiosteal abscesses. In such cases there can be an argument for withholding surgical drainage, provided there is:

a) Clear clinical improvement within 24-48 hours,

b) No decrease in visual acuity, 
c) Small $(<0.5-1 \mathrm{ml}$ in volume $)$ medially located subperiosteal abscess,

d) No significant systemic involvement,

e) Patient's age is less than 2-4 years.

Complications: 15 - 63\% patients report diplopia due to iatrogenic damage to extraocular muscles. Other complications can be postoperative bleeding, which has to be managed intraoperatively by cauterization of bleeder. Rare complications include CSF rhinorrhoea and blindness.

\section{Prognosis}

Follow up: Loss of vision in rhinosinusitis can result from central retinal artery occlusion, corneal ulceration, optic neuritis or panophthalmitis.

Summary: Orbital cellulitis in adults, as opposed to in children, is a relatively rare condition. A prompt diagnosis and treatment is necessary to avoid complications and death. The present case series is highlighted to emphasize on aggressive medical and surgical management with an aim to preserve the vision and prevent life threatening complications.

\section{Conflict of Interest}

All authors have none to declare. Appropriate permission from the concerned patients has been taken for publication of all the photos and related data.

\section{Reference}

1. Anari S, Karagama YG, Fulton B, Wilson JA (2005) Neonatal disseminated methicillin-resistant Staphylococcus aureus presenting as orbital cellulitis. J Laryngol Otol 119(1): 64-67.

2. Ferguson MP, McNab AA (1999) Current treatment and outcome in orbital cellulitis. Aust N Z J Ophthalmol 27(6): 375-379.
3. Carlisle RT, Fredrick GT (2006) Clinical review article- Preseptal and Orbital cellulitis. Hospital Physician.

4. Johnson TE, Casiano RR, Kronish JW, Tse DT, Meldrum M, et al. (1999) Sino-orbital aspergillosis in acquired immunodeficiency syndrome. Arch Ophthalmol 117(1): 57-64.

5. Emmett Hurley P, Harris GJ (2012) Subperiosteal abscess of the orbit: duration of intravenous antibiotic therapy in nonsurgical cases. Ophthal Plast Reconstr Surg 28(1): 22-26.

6. Chiu ES, Capel B, Press R, Aston SJ, Jelks EB, et al. (2006) Successful management of orbital cellulitis and temporary visual loss after blepharoplasty. Plast Reconstr Surg 118(3): 67e-72e.

7. Howe L, Jones NS (2004) Guidelines for the management of periorbital cellulitis/abscess. Clin Otolaryngol Allied Sci 29(6): 725-728.

8. Givner LB (2002) Periorbital versus orbital cellulitis. Pediatr Infect Dis J 21(12): 1157-1158.

9. Jain A, Rubin PA (2001) Orbital cellulitis in children. Int Ophthalmol Clin 41(4): 71-86.

10. Botting AM, McIntosh D, Mahadevan M (2008) Paediatric preand post-septal peri-orbital infections are different diseases. A retrospective review of 262 cases. Int J Pediatr Otorhinolaryngol 72(3): 377-383.

11. Desrosiers M, Evans GA, Keith PK, Wright ED, Kaplan A, et al. (2011) Canadian clinical practice guidelines for acute and chronic rhinosinusitis. Allergy Asthma Clin Immunol 7(1): 2.

12. Chaudhry IA, Shamsi FA, Elzaridi E, Al-Rashed W, Al-Amri A, et al. (2007) Outcome of treated orbital cellulitis from a tertiary eye care center in the Middle East. Ophthalmology 114(2): 345-354.

13. Hilal SK (1979) Computed tomography of the orbit. Ophthalmology 86(5): 864-869.

14. Kanski J (2011) Clinical Ophthalmology: A Systematic Approach ( $7^{\text {th }}$ edn); Butterworth Heinemann.

15. Maniglia AJ, Kronberg FG, Culbertson W (1984) Visual loss associated with orbital and sinus siseases. The Laryngoscope 94(8): 1050-1059.

\section{Your next submission with Juniper Publishers} will reach you the below assets

- Quality Editorial service

- Swift Peer Review

- Reprints availability

- E-prints Service

- Manuscript Podcast for convenient understanding

- Global attainment for your research

- Manuscript accessibility in different formats

( Pdf, E-pub, Full Text, Audio)

- Unceasing customer service

Track the below URL for one-step submission https://juniperpublishers.com/online-submission.php 